\title{
ALGUNS ASPECTOS EPIDEMIOLÓGICOS DOS ACIDENTES DE TRABALHO FATAIS OCORRIDOS EM CAMPINAS, SP \\ (BRASIL), 1972-1978
}

Renata Rivera Ferreira* René Mendes*

\begin{abstract}
FERREIRA, R.R. \& MENDES, R. Alguns aspectos epidemiológicos dos acidentes de trabalho fatais ocorridos em Campinas, SP (Brasil), 1972-1978. Rev. Saúde publ., S. Paulo, 15:251-62, 1981 .
\end{abstract}

RESUMO: Estudo epidemiológico de 341 acidentes de trabalho fatais ocorridos em Campinas, no periodo de 1972 a 1978, realizado a partir da consulta a arquivos do Instituto Nacional de Previdência Social (INPS). Identificaram-se como caracteres epidemiológicos predominantes $o$ acometimento de adultos jovens $(68,3 \%$ das vitimas fatais tinham menos de 40 anos), do sexo masculino $(95,6 \%)$; os "condutores de veiculos de transporte" constituiram a categoria profissional mais acometida $(19,4 \%)$, seguida da dos serventes de obras $(10,4 \%)$; a construção civil foi o ramo de atividade que mais contribuiu para a mortalidade por acidentes de trabalho $(29,9 \%)$; os "acidentes de trânsito de veículos a motor" constituiram-se na causa externa mais frequiente $(50,1 \%)$, seguindo-se o grupo dos "outros acidentes" $(22,9 \%)$ e o das "quedas acidentais" $(12,6 \%)$; os "traumatismos de crânio" foram a natureza da lesão mais frequiente. São mencionados alguns aspectos a serem considerados na prevenção, quanto à prioridade da construção civil e quanto à participação das Empresas na prevenção de acidentes de trânsito em situação ocupacional.

UNITERMOS: Acidentes do trabalho, Campinas, SP, Brasil. Epidemiologia. Segurança do trabalho. Saúde ocupacional.

\section{INTRODUCAOO}

Entre os indicadores que costumam ser empregados para avaliar a adequação das relações entre o Homem e seu ambiente de trabalho, bem como o grau de deterioração de tal equilibrio, destacam-se os acidentes de trabalho, quer por sua fácil identificação e medida, quer por sua importância intrínseca em termos de morbi-mortalidade de adultos e, consequientemente, por suas repercussões sociais e econômicas ?.
No Brasil, tal indicador passou a ser utilizado com mais freqüência, a partir de 1969 , quando, como sub-produto da unificação dos Institutos de Previdência Social, tornaram-se de conhecimento público as estatísticas nacionais de acidentes de trabalho. Tais estatísticas revelaram números absolutos e relativos de magnitude até então não imaginada, que daquele ano a esta parte evoluiram como pode ser apreciado na Tabela 1 .

- Do Departamento de Medicina Preventiva e Social da Faculdade de Clências Médicas da UNICAMP - Rua Dr. Quirino, 1856 - 13100 - Campinas, SP - Brasil. 
FERREIRA, R.R. \& MENDES, R. Alguns aspectos epidemiológicos dos acidentes de trabalho fatais ocorridos em Campinas, SP (Brasil), 1972-1978. Rev. Saude puibl., S. Paulo, 15:251-62, 1981.

T A B E L A 1

Acidentes de trabalho no Brasil, 1969 a 1979.

\begin{tabular}{c|c|c|c|c}
\hline Ano & $\begin{array}{c}\text { Número de } \\
\text { Empregados } \\
\text { Registrados }\end{array}$ & $\begin{array}{c}\text { Número de } \\
\text { Acidentes de } \\
\text { Trabalho }\end{array}$ & $\%$ & $\begin{array}{c}\text { Mortes por } \\
\text { Acidentes do } \\
\text { Trabalho }\end{array}$ \\
\hline 1969 & 7.268 .449 & 1.059 .196 & 14,57 & $\ldots$ \\
1970 & 7.284 .022 & 1.220 .111 & 16,75 & 2.232 \\
1971 & 7.764 .486 & 1.330 .523 & 17,14 & 2.587 \\
1972 & 8.148 .987 & 1.504 .723 & 18,47 & 2.805 \\
1973 & 10.956 .956 & 1.632 .696 & 14,90 & 3.122 \\
1974 & 11.537 .024 & 1.796 .761 & 15,57 & 3.764 \\
1975 & 12.996 .796 & 1.916 .187 & 14,74 & 3.942 \\
1976 & 14.945 .489 & 1.743 .825 & 11,66 & 3.900 \\
1977 & 16.590 .000 & 1.614 .750 & 9,73 & 4.445 \\
1978 & 18.500 .000 & 1.564 .380 & 8,45 & 4.342 \\
1979 & 20.322 .500 & 1.507 .930 & 7,42 & $\ldots$ \\
\hline
\end{tabular}

FONTE: INPS

Pela Tabela 1, nota-se que apesar do aparente declínio da incidência de acidentes a partir de 1973 , os acidentes de trabalho fatais crescem ano a ano em números absolutos, e em números relativos (incidência de óbitos na população de trabalhadores registrados) não têm declinado no período abrangido pelas estatisticas.

Contudo, a problemática dos acidentes de trabalho fatais não tem sido alvo da atenção de que é merecedora, quer por parte dos órgãos públicos, quer por parte das instituições envolvidas com a política de Saúde Ocupacional no pais. Escassos têm sido os estudos voltados para a análise deste grave problema de Saúde Pública 1,18, mormente utilizando uma abordagem epidemiológica que permita esclarecer fatores envolvidos em sua gênese, visando orientar medidas preventivas.

Este trabalho visa especificamente:
1. Analisar alguns parâmetros epidemiológicos (idade, sexo, estado civil, ocupação, naturalidade, procedência, tipo de acidente e/ou causa da morte, local da ocorrência e distribuição no tempo) dos acidentes de trabalho fatais ocorridos em Campinas, SP, no período de 1972-78.

2. Com base na análise epidemiológica dessas ocorrências, formular algumas sugestões destinadas a um programa que vise a controlar este problema.

\section{MATERIAL I METODOS}

Os casos estudados somam um total de 361 óbitos decorrentes de acidentes de trabalho, relativos ao período de 1972 a 1978, ocorridos ou registrados em Campinas, SP, (por razões administrativas do Instituto Nacional de Previdência Social (INPS), algumas ocorrências nos municípios de Cosmópolis, Paulínia, Valinhos e Sumaré são registradas em Campinas). 
FERREIRA, R.R. \& MENDES, R. Alguns aspectos epidemiológicos dos acidentes de trabalho fatais ocorridos em Campinas, SP (Brasil), 1972-1978. Rev. Saúde públ., S. Paulo, 15:251-62, 1981.

As informações referentes a cada caso foram obtidas através de consulta aos arquivos da Agência do INPS em Campinas, SP. De cada registro foram transcritos para um formulário, dados essenciais tais como: nome, endereço da vítima, idade, sexo, estado civil, naturalidade, procedência, ocupação, nome e endereço da empresa em que estava empregado, ramo de atividade da empresa, data, hora e local da ocorrência, tipo de acidente, causa e data da morte.

Ocorre, no entanto, que, no que concernt a 20 casos, não foi possivel, por motivos administrativos, o preenchimento adequado dos formulários, obtendo-se apenas 0 ano de ocorrência do acidente.

A caracterização e o agrupamento adequados das diversas categorias profissionais foram feitos com base na Classificação Brasileira de Ocupações, segundo as normas da Secretaria de Emprego e Salário, do Ministério do Trabalho ${ }^{3}$.

As causas de mortalidade, assim como as causas externas das lesões, caracterizadas segundo a descrição do acidente, foram consideradas e agrupadas segundo a Lista A, da Classificação Internacional de Doenças, 9a Revisão.9

\section{RESULTADOS E COMENTARIOS}

Pela análise da Tabela 2 é possível verificar que o número absoluto de óbitos manteve-se aparentemente constante entre os anos de 1973 a 1978.

Uma avaliação em relação ao número de empregados segurados não foi possivel, pois tal número, em termos regionais, inexiste em qualquer das instituições relacionadas com Trabalho, Indústria e Comércio e mesmo Previdência Social.

Considerando-se tão somente os dados da Tabela 2 e tomando-se os anos em que o número absoluto de acidentes de trabalho fatais atingiu seus valores máximo e mínimo - 1977 e 1972, respectivamente - verifica-se que houve um aumento em torno de $100 \%$. Este fato merece ser destacado, uma vez que nos anos anteriores aos abrangidos pelo estudo $-1969,1970,1971$ - o número absoluto de mortes por acidentes de trabalho manteve-se aparentemente constante, apresentando cifras de 29 , 31 e 31 , respectivamente, segundo informações coletadas na Agência do INPS em Campinas. Dessa maneira, ganha maior importância a já significativa elevação do número de casos, observada em 1973.

T A B E L A 2

Acidentes de trabalho fatais segundo o ano de ocorrência, Campinas, SP, 1972-1978.

\begin{tabular}{lcr}
\hline Ano & Número & $\%$ \\
\hline 1972 & 28 & 7,8 \\
1973 & 57 & 15,8 \\
1974 & 53 & 14,7 \\
1975 & 53 & 14,7 \\
1976 & 56 & 15,5 \\
1977 & 60 & 16,6 \\
1978 & 54 & 14,9 \\
\hline Total & & 100,0 \\
\hline
\end{tabular}

T A B E L A 3

Acidentes de trabalho fatais segundo a idade, Campinas, SP, 1972-1978.

\begin{tabular}{lcr}
\hline Faixas etárias & $N \%$ & $\%$ \\
\hline$<20$ anos & 33 & 9,7 \\
$20 \mid-30$ anos & 117 & 34,3 \\
$30-40$ anos & 83 & 24,3 \\
$40 \mid-60$ anos & 63 & 18,5 \\
$50 \mid-60$ anos & 31 & 9,1 \\
60 anos e mais & 14 & 4,1 \\
\hline Total & 341 & 100,0 \\
\hline
\end{tabular}


FERREIRA, R.R. \& MENDES, R. Alguns aspectos epidemiologicos dos acidentes de trabalho fatais ocorridos em Campinas, SP (Brasil), 1972-1978. Rev. Saúde públ., S. Paulo, 15:251-62, 1981.

TA B E L A 4

Acidentes de trabalho fatais segundo o sexo, Campinas, SP, 1972-1978.

\begin{tabular}{lrr}
\hline Sexo & N9 & $\%$ \\
\hline Masculino & 326 & 95,6 \\
Feminino & 15 & 4,4 \\
\hline Total & 341 & 100,0 \\
\hline
\end{tabular}

TA B E L A 5

Acidentes de trabalho fatais segundo o estado civil, Campinas, SP, 1972-1978.

\begin{tabular}{lcr}
\hline Estado civil & No & $\%$ \\
\hline Solteiro & 123 & 36,0 \\
Casado & 214 & 62,8 \\
Viúvo & 3 & 0,9 \\
Desquitado & 1 & 0,3 \\
Total & 341 & 100,0 \\
\hline
\end{tabular}

Quanto ao grupo etário atingido, é importante destacar que estão sendo vitimados, por mortes prematuras e evitáveis, individuos extremamente jovens: mais de $2 / 3$ das vítimas fatais tinham menos de 40 anos, encontrando-se, portanto, em plena fase produtiva de sua vida (Tabela 3 ). Se for considerado que a imensa maioria das vitimas é do sexo masculino $(95,6 \%)$, é possivel imaginar as profundas repercussões sociais e econômicas, principalmente em nivel familiar $(62,8 \%$ das vitimas eram casadas) (Tabelas 4 e 5 ).

Os dados apresentados na Tabela 6 , se receberem um enfoque de acordo com 0 ramo de atividade da empresa, mostrarão destaque significativo para a construção civil, com cerca de $30 \%$ de todas as ocorrências fatais. A importâncịa dessa área torna-se incontestável quando se verifica que os demais ramos de alto risco comércio varejista, transporte rodoviário e indústria química - apenas somam um total aproximado de $24 \%$ das ocorrências.

Para explicar a incômoda posição da construção civil na problemática dos acidentes de trabalho, costumam ser citados alguns fatores, tais como: $2,4,12,14$

- grande diversidade de operações (movimento de terra, fundação, trabalho em profundidade, trabalho em altura, trabalhos especializados, entre outros), com grande diversidade de riscos;

- em comparação com outros ramos industriais, curta duração do "estabelecimento", provocando pouco interesse na implantação de programas de prevenção e dificuldade na fiscalização adequada;

- baixa qualificação da mão-de-obra, geralmente com precárias condições de saúde, habitação, nutrição, entre outros;

- variedade de empresas trabalhando no mesmo canteiro de obras, provocando a diluição da responsabilidade pelos programas de prevenção;

- ramo industrial altamente "pulverizado", com predomínio da pequena empresa, com suas tradicionais características de reduzida especialização na administração, inadequação dos métodos e processos, ineficiência e obsoletismo de equipamentos e instalaçōes ${ }^{11}$;

- os trabalhos de construção civil desenvolvidos, freqüientemente, em condições geográficas e climáticas extremamente adversas, como é o caso das construções de barragens, estradas e outras obras públicas.

A observação conjunta da Tabela 6 com a Tabela 7 , onde os acidentes encontram-se distribuídos segundo a causa externa da lesão em cada ramo de atividade, permite 
FERREIRA, R.R. \& MENDES, R. Alguns aspectos epidemiológicos dos acidentes de trabalho fatais ocorridos em Campinas, SP (Brasil), 1972-1978. Rev. Saúde públ., S. Paulo, 15:251-62, 1981.

inferir que acidentes fatais na construção civil, em sua maioria, são provocados por "acidentes de veículos a motor" $(38,2 \%)$, seguidos dos "acidentes industriais" $(29,4 \%)$ e pelas "quedas acidentais" $(\mathbf{2 5 , 5 \% )}$. Os primeiros - acidentes de veiculos a motor - incluem, naturalmente, o transporte dos trabalhadores. Quase 30\% das mortes de pedreiros e de serventes de pedreiro deveram-se a tal tipo de acidente. Tais observações, por si, ịá apontam diretrizes para uma politica de prevenção.

Aliás, a apreciação da Tabela 7 , bem como da Tabela 8, permite destacar a importância assumida pelos acidentes de veículos a motor no contexto dos acidentes de trabalho fatais. Em Campinas, no período considerado neste estudo, os acidentes de trânsito significam cerca de $50 \%$ de todos os acidentes de trabalho fatais. Evidentemente, em algumas categorias profissionais - os condutores de veículos de transporte, por exemplo - eles ocupam proporção ainda mais elevada.

Convém lembrar que na legislação de acidentes de trabalho, são previstas diferentes situações em termos de acidentes de trânsito: se eles ocorrerem em motoristas profissionais e seus ajudantes, são considerados acidentes de trabalho "tipo" ou "típicos"; se ocorrerem durante a locomoção de trabalhadores outros, indo ou voltando de seu local de trabalho, os acidentes de trânsito passam a ser configurados como "acidentes de trajeto", ou in itinere. Embora sutil, tal diferença tem evidentes implicações que devem ser consideradas no delineamento das políticas de prevenção.

Entre nós, vários estudos têm chamado à atenção para o significado crescente e a tendência epidêmica dos acidentes de trânsito. Assim, Fávero ${ }^{5}$ analisou em profundidade o problema na cidade de Ribeirão Preto, SP; Laurenti e col. ${ }^{8}$ estudaram aspectos epidemiológicos dos acidentes de trânsito na cidade de São Paulo; Pugliese e col.tn analisaram a questão na cidade de Salvador, BA. Recentemente, Mello Jorge ${ }^{10}$ reviu $O$ importante tema ao analisar a mortalidade por causas violentas no município de São Paulo.

$\mathrm{Na}$ verdade, os acidentes de trânsito que vitimam empregados em atividade profissional, ou empregados dirigindo-se ao seu local de trabalho ou dele voltando, representam ponto de confluência de dois problemas de Saúde Pública de importância crescente 7,15,17. Entre os acidentes de trânsito destacam-se os atropelamentos, e Pinto ${ }^{15}$ estima que mais de $50 \%$ dos atropelamentos são acidentes de trabalho. Este problema é particularmente importante quando o estabelecimento de trabalho situa-se na margem de vias ou estradas de tráfego intenso.

Conseqüentemente, a busca de soluções transcende as iniciativas dos órgãos oficiais diretamente envolvidos com o problema dos acidentes de trânsito, exigindo a colaboração das empresas, ainda que suas ações estejam restritas ao grupamento social constituído por seus empregados e suas famílias. ${ }^{13} \mathrm{Um}$ exemplo típico de tal colaboração (ou responsabilidade) é a construção de passarelas em locais estratégicos próximos aos estabelecimentos de trabalho.

Evidência-se a importância dos traumatismos de crânio entre os acidentes de trabalho fatais, presentes em $54,5 \%$ de todos os óbitos. Tal aspecto com suas profundas implicaçōes de ordem preventiva, terapêutica e de reabilitação foi anteriormente apreciado na literatura nacional, entre outros, por Finocchiaro," que, aliás, encontrou cifras semelhantes em sua casuística. As "quedas acidentais" representam a terceira causa de morte por acidente de trabalho. No ramo da construção civil e, particularmente intre pedreiros, serventes de obras, eletricistas e carpinteiros esta causa tem posição de destaque, lembrando o risco do trabalho em andaimes desprotegidos, em escadas e em telhados $2,4,12,11$. 
FERREIRA, R.R. \& MENDES, R. Alguns aspectos epidemiológicos dos acidentes de trabalho fatais ocorridos em Campinas, SP (Brasil), 1972-1978. Rev. Saúde públ., S. Paulo, 15:251-62, 1981.

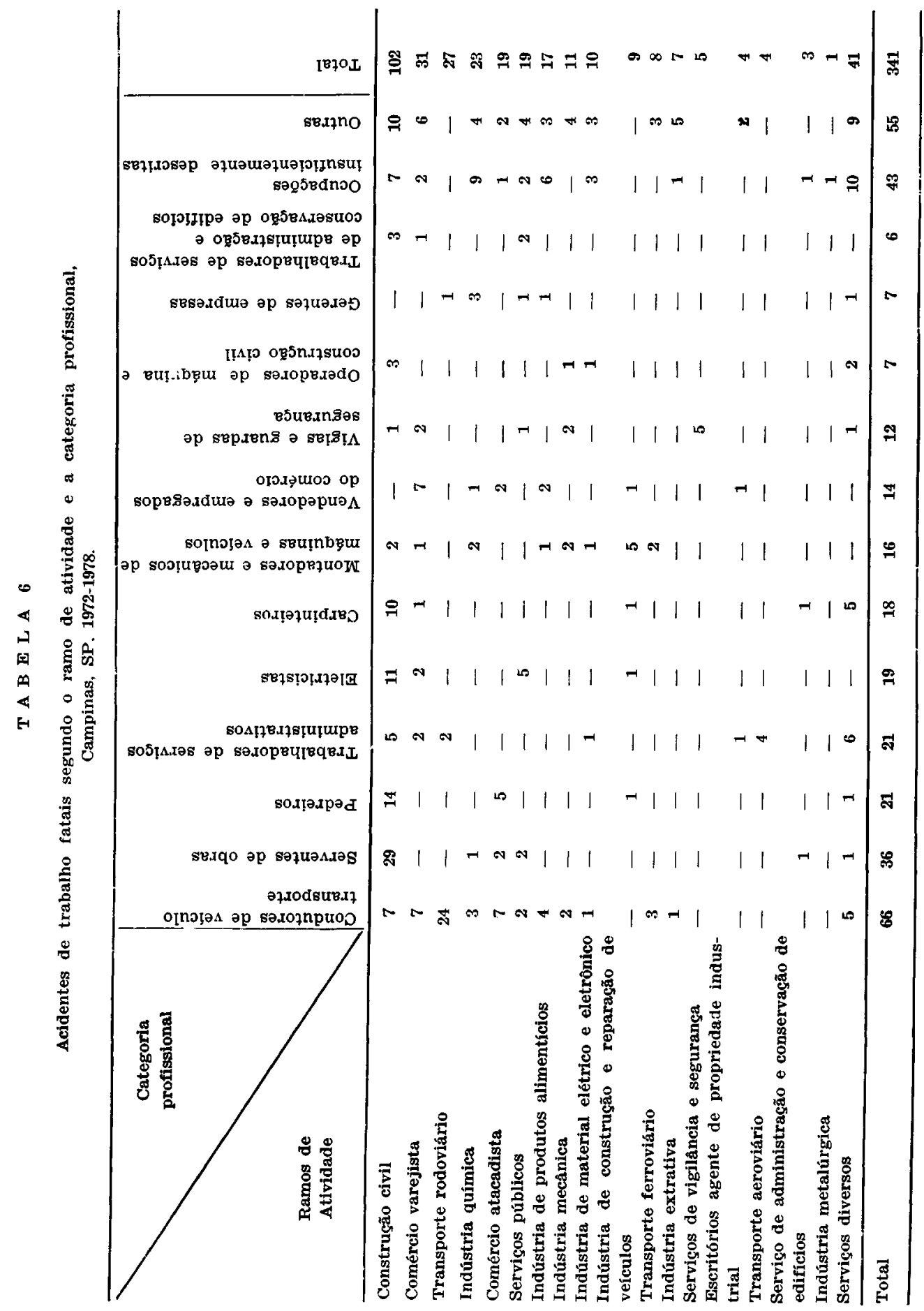




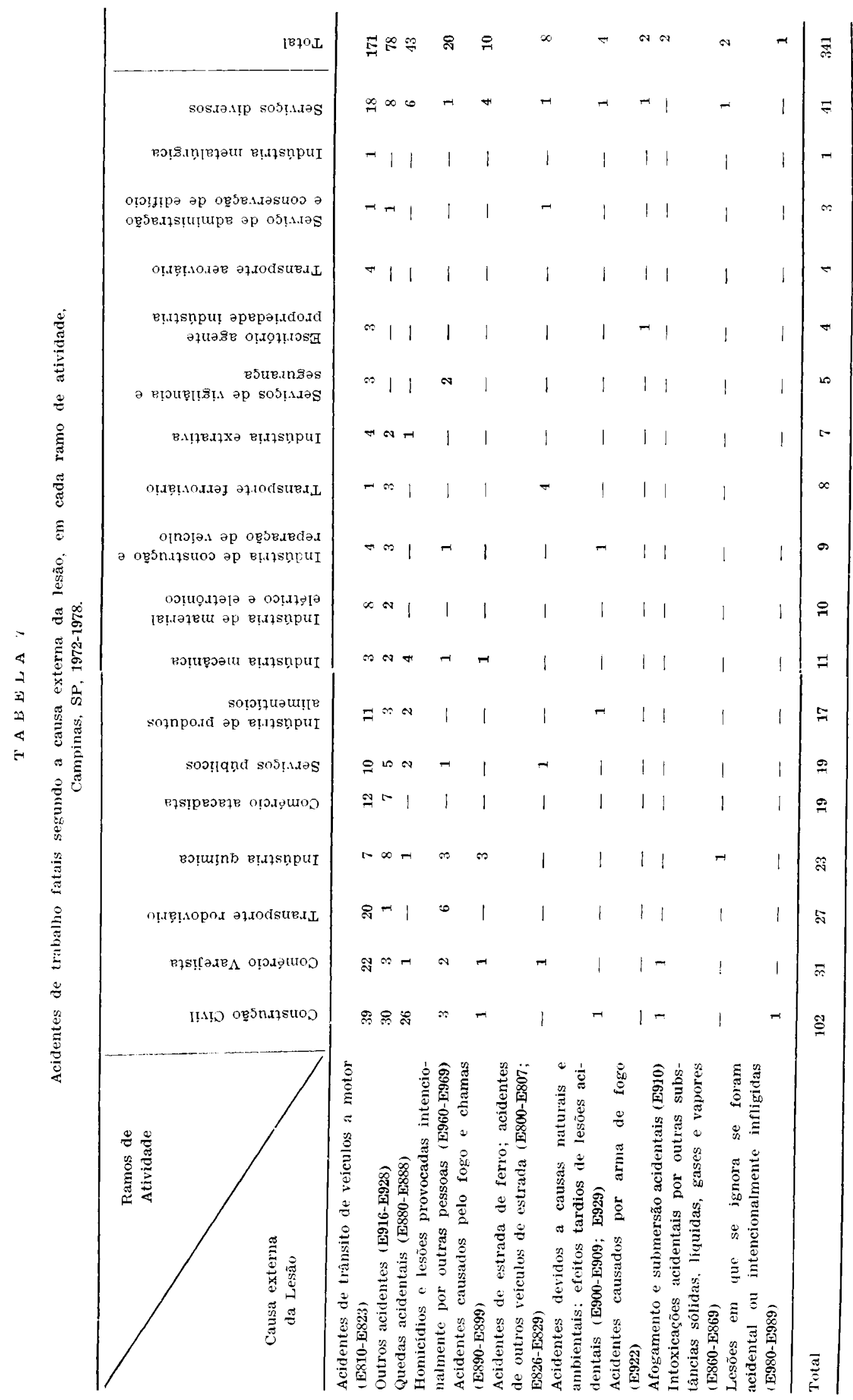


FERREIRA, R.R. \& MENDES, R. Alguns aspectos epidemiológicos dos acidentes de trabalho fatais ocorridos em Campinas, SP (Brasil), 1972-1978. Rev. Saúde públ., S. Paulo, 15:251-62, 1981.

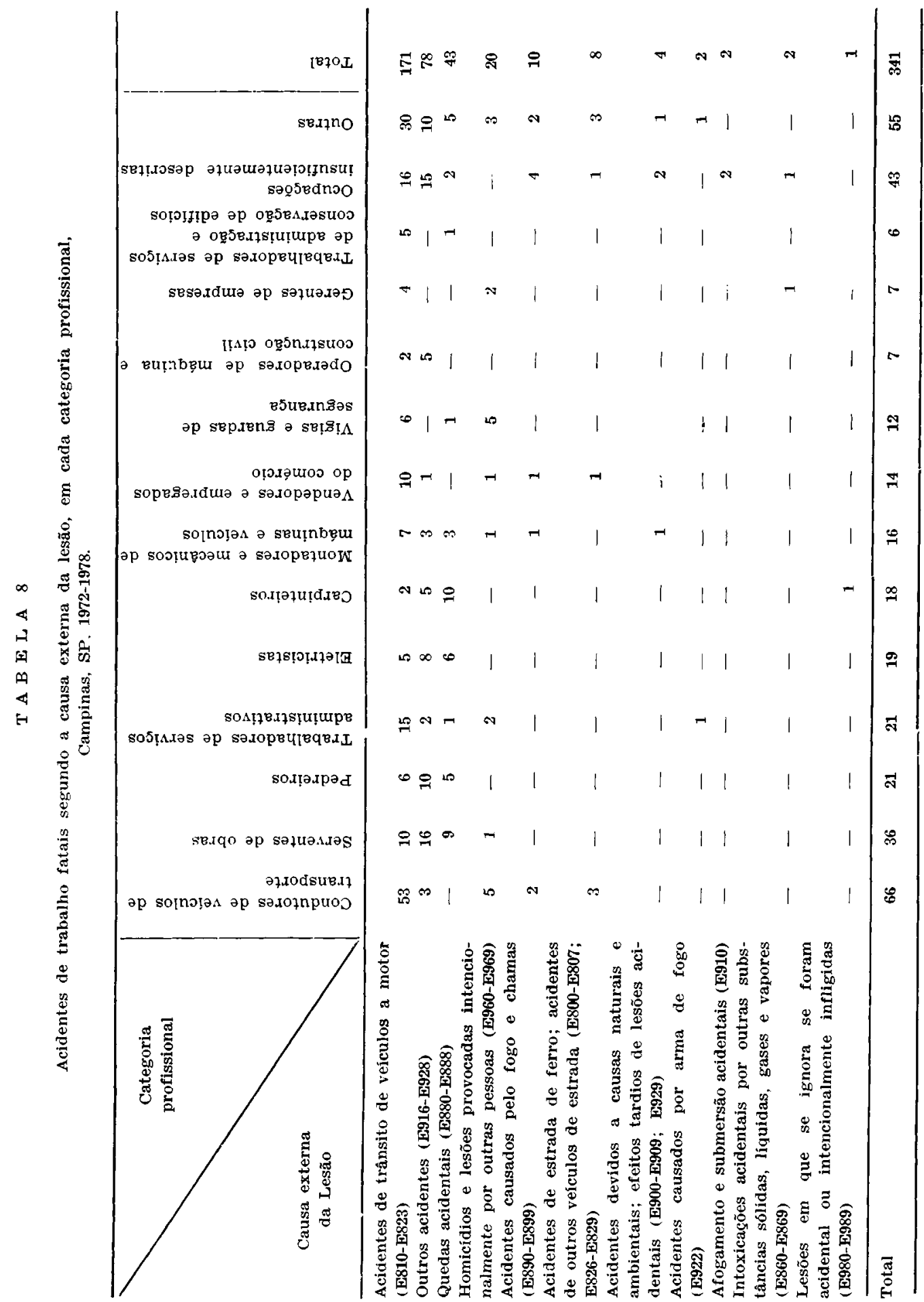




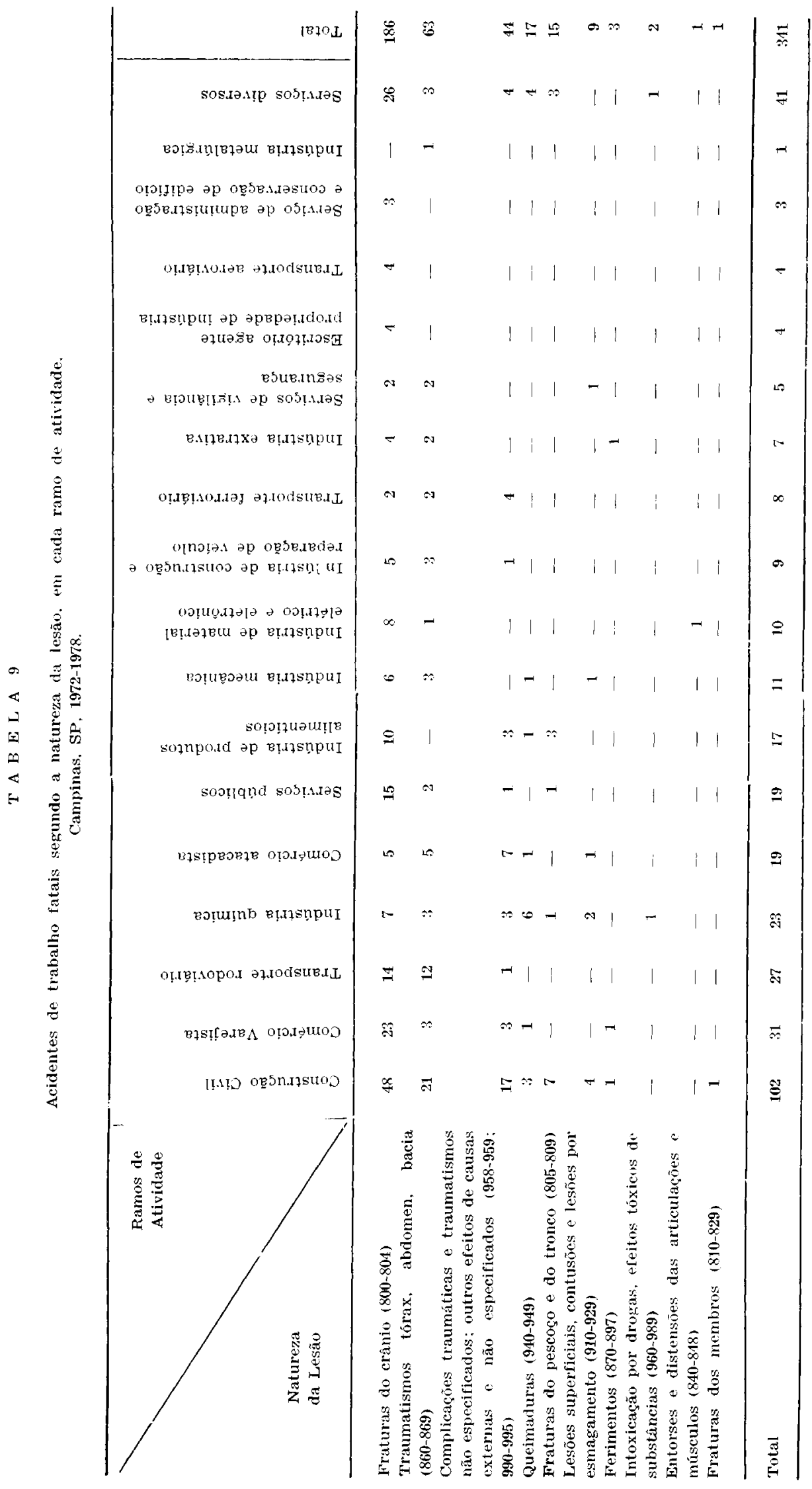


FERREIRA, R.R. \& MENDES, R. Alguns aspectos epidemiológicos dos acidentes de trabalho fatais ocorridos em Campinas, SP (Brasi1), 1972-1978. Rev. Saúde puibl., S. Paulo, 15:251-62, 1981.

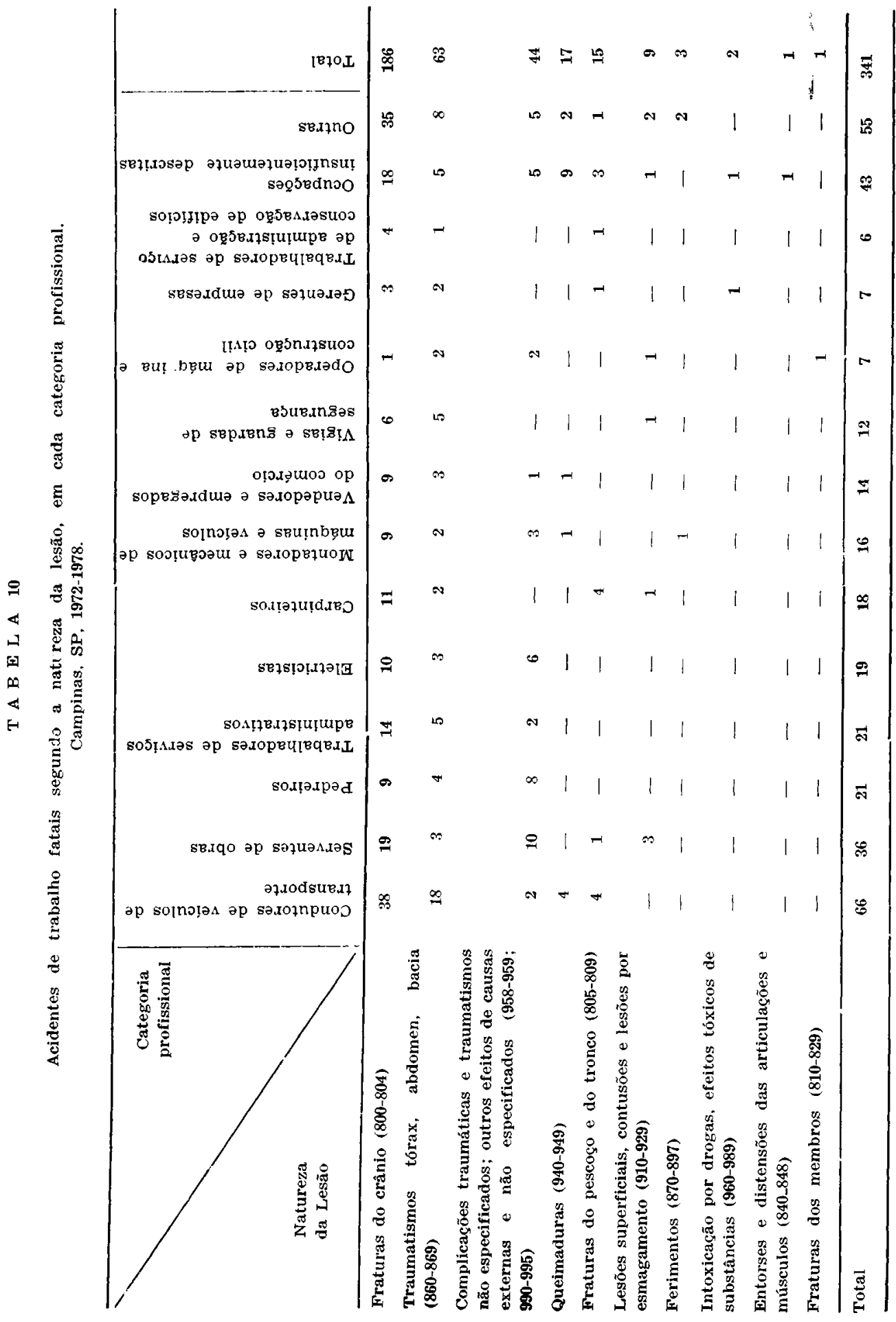


FERREIRA, R.R. \& MENDES, R. Alguns aspectos epidemiológicos dos acidentes de trabalho fatais ocorridos em Campinas, SP (Brasil), 1972-1978. Rev. Saúde públ., S. Paulo, 15:251-62, 1981.

\section{CONCLUSŐES E RECOMENDAÇÖES}

1. Tomando como base os registros das ocorrências em Campinas, SP, de 1972 a 1978, constituem-se caracteres epidemiológicos dos acidentes de trabalho fatais:

a) o acometimento predominante de adultos jovens $(68,3 \%$ das vitimas fatais tinham menos de 40 anos), do sexo masculino $(95,6 \%)$;

b) os "condutores de veículos de transporte" como a categoria profissional mais acometida $(19,4 \%)$, seguida da dos serventes de obras $(10,4 \%)$;

c) a construção civil como o ramo de atividade que mais contribui para a mortalidade por acidentes de trabalho $(29,9 \%)$;

d) os "acidentes de trânsito de veículos a motor" como a causa externa mais frequiente nos acidentes de trabalho fatais $(50,1 \%)$; seguem-se o grupo de "outros acidentes" $(22,9 \%)$ e o das "quedas acidentais" $(12,6 \%)$;

e) os "traumatismos de crânio" como a natureza da lesão mais freqüente nos acidentes de trabalho fatais $(54,5 \%)$; seguem-se os "traumatismos de tórax, abdome e bacia" $(18,5 \%)$ e as "com- plicações traumáticas e traumatismos năo especificados e outros efeitos, de causas não especificadas" (12,9\%).

2. A análise epidemiológica dessas ocorrências permite que seiam menciunados alguns aspectos a serem considerados quando da formulação da politica de prevenção de acidentes de trabalho, principalmente os graves e mortais:

a) conceder elevada prioridade ao ramo da construção civil, onde, além de outros problemas de grande complexidade, destacam-se os riscos ocupacionais ligados ao transporte dos trabalhadores e o trabalho em andaimes $e$ outros locais elevados, sem a devida proteção;

b) considerar como indissociáveis os acidentes de trabalho e os de trânsito, quando estes estiverem relacionados a situações ocupacionais (motoristas profissionais, transporte de trabalhadores, atropelamentos nas vizinhanças dos locais de trabalho entre outros). Além das implicações previstas em lei, deve ser claramente definida a responsabilidade da empresa, em termos de participação na prevenção.

FERREIRA, R.R. \& MENDES, R. [Epidemiological aspects of fatal occupational accidents, Campinas, SP (Brazil), 1972-1978]. Rev. Saúde públ., S. Paulo, 15: 251-62, 1981.

ABSTRACT: Scrutiny of INPS (National Institute of Social Welfare) files resulted in a epidemiologic survey of 341 fatal occupational accidents in Campinas, SP (Brazil), that occurred between 1972 and 1978. The main epidemiologic types were: violent incidents resulting in the death of young adults $(63.3 \%$ were under 40 and $95.6 \%$ were male); the professional category most victimized was that of the transport vehicle drivers $(19.4 \%)$, followed by construction helpers $(10.4 \%)$; construction work as an activity held the highest occupational accident mortality $(29.9 \%)$; motor vehicle traffic accidents were the most frequent external causes of death $(\mathbf{5 0 . 1 \%})$ and was followed by other accidents $(22.9 \%)$ and accidental falls $(12.6 \%)$; skull trauma was the most frequent lesion-type injury. Considering these statistics, certain aspects of prevention were stressed with priority being given to civil construction and to company participation in the prevention of traffic accidents when the vehicle is being used for company purposes.

UNITERMS: Accidents, industrial, Campinas, SP, Brazil. Epidemiology. Occupational safety. Occupational health. 
FERREIRA, R.R. \& MENDES, R. Alguns aspectos epidemiológicos dos acidentes de trabalho fatais ocorridos em Campinas, SP (Brasil), 1972-1978. Rev. Saúde públ., S. Paulo, 15:251-62, 1981.

\section{REFERENCIAS BIBLIOGRAFICAS}

1. BRANDAO, M.E.C. et al. Aspectos de segurança e higiene nos óbitos por acidentes do trabalho. In: Congresso Nacional de Prevenção de Acidentes do Trabalho, 119, Curitiba, 1972. Anais. Rio de Janeiro, DNSHT, 1972, p. 364-7.

2. CABRERA, I.T. Prevenção de acidentes do trabalho na indústria da construção civil. São Paulo, Fundacentro, 1971.

3. ClASSIFICAÇAOO Brasileira de Ocupaçōes; Portaria no 13 da Secretaria de Emprego e Salário. Diário Oficial da Uniāo, Brasília 22 jun. 1978.

4. DUCA, A.C.L. et al. Proposta de um check-list para inspeção em obras de construção civil. In: Congresso Nacional de Prevenção de Acidentes do Trabalho, 16\%, Porto Alegre, 1977. Ancis. São Paulo, Fundacentro, 1977. p. 294-9.

5. FAVERO, M. Estudo epidemiológico dos acidentes de transito em Ribeirão Preto. Ribeirão Preto, 1971. [Tese de Doutoramento - Faculdade de Medicina de Ribeirão Preto da USP].

6. FINOCCHIARO, J, Considerações subre a gravidade do traumatismo craniano na infortunistica. Rev. bras. Saúde ocup., $6: 6-12,1978$.

7. LAURENTI, R. O problema das doenças crónicas e degenerativas e dos acidentes nas áreas urbanizadas da América Latina. Rev. Saúde públ., S. Paulo, 9:239-48, 1975.

8. LAURENTI, $R$. et al. Alguns aspectos epidemiológicos da mortalidade por acidentes de trânsito de veículos a motor na cidade de São Paulo, Brasil. Rev. Saûde puibl., S. Paulo, 6:329-41, 1972.

9. MANUAL da classificação estatística internacional de doenças, lesóes e cal'sas de óbito: 9a revisão, 1975. São Paulo, Centro Brasileiro de Classificação de Doenças, 1978.

10. MELLO JORGE, M.H.P. Mortaliaade por causas violentas no Municipio de São Paulo. São Paulo, 1979. [Tese de Doutoramento - Faculdade de Saúde Pública da USP]
11. MENDES, R. Importancia das pequenas empresas industriais no problema de acidentes do trabalho em São Paulo. São Paulo, 1975. [Dissertação de Mestrado - Faculdade de Saúde Pública da USP]

12. MILlAR, J.M.N. et al. Acidentes e doenças profissionais na construção civil: um estudo, uma pesqliisa, uma proposta. Os caminhos para a efetividade no controle de riscos. In: Congresso Nacional de Prevenção de Acidentes do Trabalho, 15\%, Rio de Janeiro, 1975. Anais. Săo Paulo, Fundacentro, 1975. p. 887-900.

13. NOGUEIRA, N. Educação de trânsito, prioridade nacional. Saúde ocup. seg., $13: 265-75,1978$.

14. PEREIRA, C.A. \& ZAIA, P.A. Construção civil na Capital de São Paulo: assistência médica e prevenção de acidentes do trabalho. In: Congresso Nacional de Prevenção de Acidentes do Trabalho, $11^{\circ}$, Curitiba, 1972. Anais. Rio de Janeiro, DNSHT, 1972. p. 419-45.

15. PINTO, J.B. Os atropelamentos como acidentes do trabalho. In: Congresso $\mathrm{Na}$ cional de Prevenção de Acidentes do Trabalho, 13, São Paulo, 1974. Anais. São Paulo, Fundacentro, 1974. p. 443-7.

16. PUGLIESE, C. et al. Aspectos epidemiológicos dos acidentes fatais a veículo a motor na cidade de Salvador (Bahia), Brasil. Rev. Saude puibl., \$. Paulo, $9: 271-83,1975$.

17. RAMOS, J.V. et al. A segurança no trânsito, novo conceito de segurança do trabalho. In: Congresso Nacional de Prevenção de Acidentes do Trabalho, $13^{\circ}$, São Paulo, 1974. Anais. São Paulo, Fundacentro, 1974. p. 787-93.

18. SEGRE, M. \& PASCOA, M.P. Acidentes do trabalho incapacitantes e mortais em região pouco industrializada: Botucatu-SP. In: Congresso Nacional de Prevenção de Acidentes do Trabalho, 13", São Paulo, 1974. Anais. São Paulo, Fundacentro, 1974. p. 389-408.

Recebido para publicacão em 27/11/1980

Aprovado para publicação em 11/03/1981 